\title{
Comparing Aye-Aye (Daubentonia madagascariensis) Presence and Distribution between Degraded and Non-Degraded Forest within Ranomafana National Park, Madagascar
}

\author{
Zach J. Farris $^{a} \quad$ Toni Lyn Morelli ${ }^{b}$ Timothy Sefczek ${ }^{c}$ \\ Patricia C. Wright ${ }^{\mathrm{d}}$ e \\ a Department of Biology, University of Arkansas at Little Rock, Little Rock, Ark., ${ }^{\text {b Museum of }}$ \\ Vertebrate Zoology, University of California, Berkeley, Calif., ' Department of Anthropology, \\ San Diego State University, San Diego, Calif., and ${ }^{\mathrm{d} D e p a r t m e n t}$ of Anthropology,

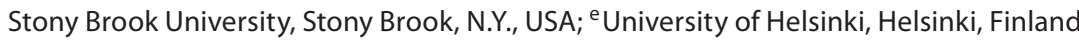

\section{Key Words}

Daubentonia madagascariensis $\cdot$ Lemur $\cdot$ Canarium $\cdot$ Secondary signs $\cdot$ Feeding sites $\cdot$ Population density $\cdot$ Optimal feeding

\begin{abstract}
The aye-aye is considered the most widely distributed lemur in Madagascar; however, the effect of forest quality on aye-aye abundance is unknown. We compared ayeaye presence across degraded and non-degraded forest at Ranomafana National Park, Madagascar. We used secondary signs (feeding sites, high activity sites) as indirect cues of aye-aye presence and Canarium trees as an indicator of resource availability. All 3 measured variables indicated higher aye-aye abundance within non-degraded forest; however, the differences across forest type were not significant. Both degraded and non-degraded forests showed a positive correlation between feeding sites and high activity sites. We found that Canarium, an important aye-aye food source, was rare and had limited dispersal, particularly across degraded forest. This preliminary study provides baseline data for aye-aye activity and resource utilization across degraded and non-degraded forests.

Copyright $\odot 2011$ S. Karger AG, Basel
\end{abstract}

\section{Introduction}

Aye-ayes (Daubentonia madagascariensis) are best known for their distinctive morphological characteristics (rodent-like incisors, specialised middle digits and bat-like ears), adaptations to their unique feeding behaviour known as 'percussive

\begin{tabular}{|c|c|}
\hline RGER & $\begin{array}{l}\text { (C) } 2011 \text { S. Karger AG, Basel } \\
0015-5713 / 11 / 0822-0094 \$ 38.00 / 0\end{array}$ \\
\hline $\begin{array}{l}\text { Fax +41 } 613061234 \\
\text { E-Mail karger@karger.ch } \\
\text { www.karger.com }\end{array}$ & $\begin{array}{l}\text { Accessible online at: } \\
\text { www.karger.com/fpr }\end{array}$ \\
\hline
\end{tabular}

Zach J. Farris

Virginia Polytechnic Institute and State University Department of Fisheries and Wildlife Sciences Cheatham Hall 124, Blacksburg, VA 24061 (USA) E-Mail zjfarris@vt.edu 
foraging' [Gibson, 1986; Milliken et al., 1991; Sterling and Povinelli, 1996]. This combination of specialised morphological and behavioural traits has allowed the aye-aye to specialise in removing and ingesting extractive foods such as embedded larvae or seeds of Canarium spp. trees (Burseraceae) [Petter, 1977; Sterling, 1994; Goodman and Sterling, 1996]. Additionally, the aye-aye's feeding plasticity has allowed it to fill a wide ecological niche by exploiting foods such as seeds, nectar, insect larvae, cultivated crops, fruits and a cankerous growth on Intsia bijuga (Fabaceae) [Pollock et al., 1985; Iwano and Iwakawa, 1988; Sterling, 1993, 2003; Andriamasimanana, 1994; Sterling et al., 1994].

As a result of their varied diet, aye-ayes occur in various habitats throughout Madagascar, including primary and secondary rainforest, deciduous forests, highly degraded landscapes and plantations [Ganzhorn and Rabesoa, 1986; Iwano et al., 1991; Simons, 1993; Sterling, 1993; Ancrenaz et al., 1994; Feistner and Schmid, 1999]. In fact, the aye-aye may be the most widespread lemur in Madagascar [Sterling, 2003]. However, despite the aye-aye's broad distribution, their numbers are still constrained by deforestation, food availability and their need for large home ranges. In addition, aye-ayes are experiencing further pressure from villagers that kill them in response to aye-aye crop raiding and local 'fady' (taboo) against the species [Sterling and Feistner, 2000; Sterling, 2003; Glaw et al., 2008; Andrainarivo et al., 2009]. As a result, the IUCN currently classifies the aye-aye as near threatened [Andrainarivo et al., 2009]. Because of their cryptic behaviour and large home ranges, little information exists concerning population dynamics and density throughout Madagascar [Sterling, 1993, 2003]. As a result, questions remain concerning the aye-aye's ability to maintain sustainable populations within the increasingly degraded habitats of Madagascar.

Aye-ayes feed heavily on the fat- and nutrient-rich seeds of Canarium trees [Sterling et al., 1994; Goodman and Sterling, 1996]. In fact, Sterling [1993] found that ayeayes spent $30 \%$ (hot, wet season) to $80 \%$ (hot, dry season) of their feeding time on Canarium seeds when available, thus feeding on Canarium 10 months out of the year. Aye-aye distribution may be closely tied to the availability of Canarium, as it is hypothesised to be their primary food source [Iwano and Iwakawa, 1988]; however, to date, no study has shown a correlation between this important food source and aye-aye density.

Aye-ayes exhibit optimal foraging by opening only the 2 larger sides of the 3-loculed seeds of Canarium trees [Iwano and Iwakawa, 1988]. Additionally, aye-ayes may optimise foraging efforts by revisiting highly productive and established feeding sites within their home range over the course of months, and possibly years [Ganzhorn and Rabesoa, 1986]. However, little research has focused on the use and reuse of highly productive feeding sites by aye-ayes. During a preliminary analysis of ayeaye presence within Ranomafana National Park (RNP), Farris [2006] randomly surveyed trails across the Talatakely trail system during the hot, wet season in search of aye-aye feeding and nest sites, counting the number of gnaw marks at each feeding site location. Farris [2006] found the majority (79/89) of sites containing signs of ayeaye feeding had approximately 5 or fewer gnaw marks. However, a few locations $(8 / 89)$ contained many more gnaw marks (approx. 10-20), revealing a strong concentration of aye-aye activity within the area. Finally, Farris observed a large number of gnaw marks (in some cases more than 100) at a few feeding sites (2/89). These feeding sites, referred to as 'aye-aye trees' by locals, may be established revisit sites with 
extensive resource availability. These aye-aye trees were resurveyed throughout the course of this preliminary study to monitor aye-aye activity and resource availability (based on secondary signs) at these sites. Moreover, anecdotal evidence provided by local guides concerning these high activity sites provided further confirmation of their extensive resource availability and their usefulness in locating aye-ayes. The preliminary study suggested that the number and distribution of these high activity sites (i.e. aye-aye trees) could reliably indicate resource availability and aye-aye activity, and thus might be useful to indicate the presence and distribution of aye-ayes across forest sites.

For this study, we used indirect methods to compare aye-aye presence and distribution, based on secondary signs (feeding sites and high activity sites) and resource availability (Canarium trees), across degraded and non-degraded forests at RNP, Madagascar. To date, no study has compared aye-aye presence and resource availability across degraded and non-degraded forests. As a result, we do not know the degree to which habitat fragmentation, human encroachment and other invasive pressures associated with degraded forests are affecting aye-aye populations. We predicted that secondary signs would show evidence of higher aye-aye activity in nondegraded forest as these forests are expected to have a greater number and more uniform distribution of resources (particularly Canarium). Further, we predicted there would be little distinction in aye-aye activity among various elevation ranges, as evidence of aye-aye feeding has been recorded for wide elevation ranges across Madagascar.

\section{Methods}

\section{Study Site}

We conducted this study in the south-eastern submontane rainforest of RNP, which has one of the highest levels of primate biodiversity in the world, with at least 12 species of lemurs, including the aye-aye [Wright, 1997]. Aye-aye population density is unknown at RNP; however, presence has been documented based on a limited number of sightings and multiple secondary signs on trees and Canarium seeds [V.J. Baptiste and R. Justin, pers. commun.].

RNP has a seasonal, subtropical environment that averages 2.5-4 $\mathrm{m}$ of rain/year. We conducted this field study during the warm season, from October 15 to December 15, 2005. Elevation ranges from 500 to $1,500 \mathrm{~m}$ within the park.

Three main trail systems exist within RNP: Valohoaka $\left(1.36 \mathrm{~km}^{2}\right)$, Vatoharanana $(0.71$ $\left.\mathrm{km}^{2}\right)$ and Talatakely $\left(2.1 \mathrm{~km}^{2}\right)$, as well as a major transect, Vohipaharara. Each trail system consists of at least 50 trails ranging from $20 \mathrm{~m}$ to more than $1,500 \mathrm{~m}$ in length. The 3 trail systems lie south of the Namorona River, which bisects RNP; Vohipaharara is found north of the river near a small village and contains one $4-\mathrm{km}$ transect (fig. 1). Trails within each trail system have been established over the past 20 years by researchers and tourist guides based on lemur home ranges (primarily for observing Hapalemur spp. and Propithecus edwardsii), and, therefore, trails encompass a number of habitat types and topographic features. Two trail systems (Vatoharanana and Valohoaka) feature non-degraded rainforest habitat with the remaining trail system and transect (Talatakely and Vohipaharara) located in degraded habitat [White et al., 1995; Wright, 1995; Tecot, 2008]. Differences in forest composition (e.g. tree density, height, diameter at breast height, canopy cover, crown depth, species richness, spatial dispersion of trees, microhabitat, forest biomass and others) exist for degraded and non-degraded forests at RNP [Balko, 1998; Grassi, 2001; Balko and Underwood, 2005; Tecot, 2008]. For instance, in degraded forests, Canarium trees were selectively logged, and the pioneer species Ravenala spp. has become more prevalent. Further, Tecot [2008] recently surveyed 6 botanical plots across 


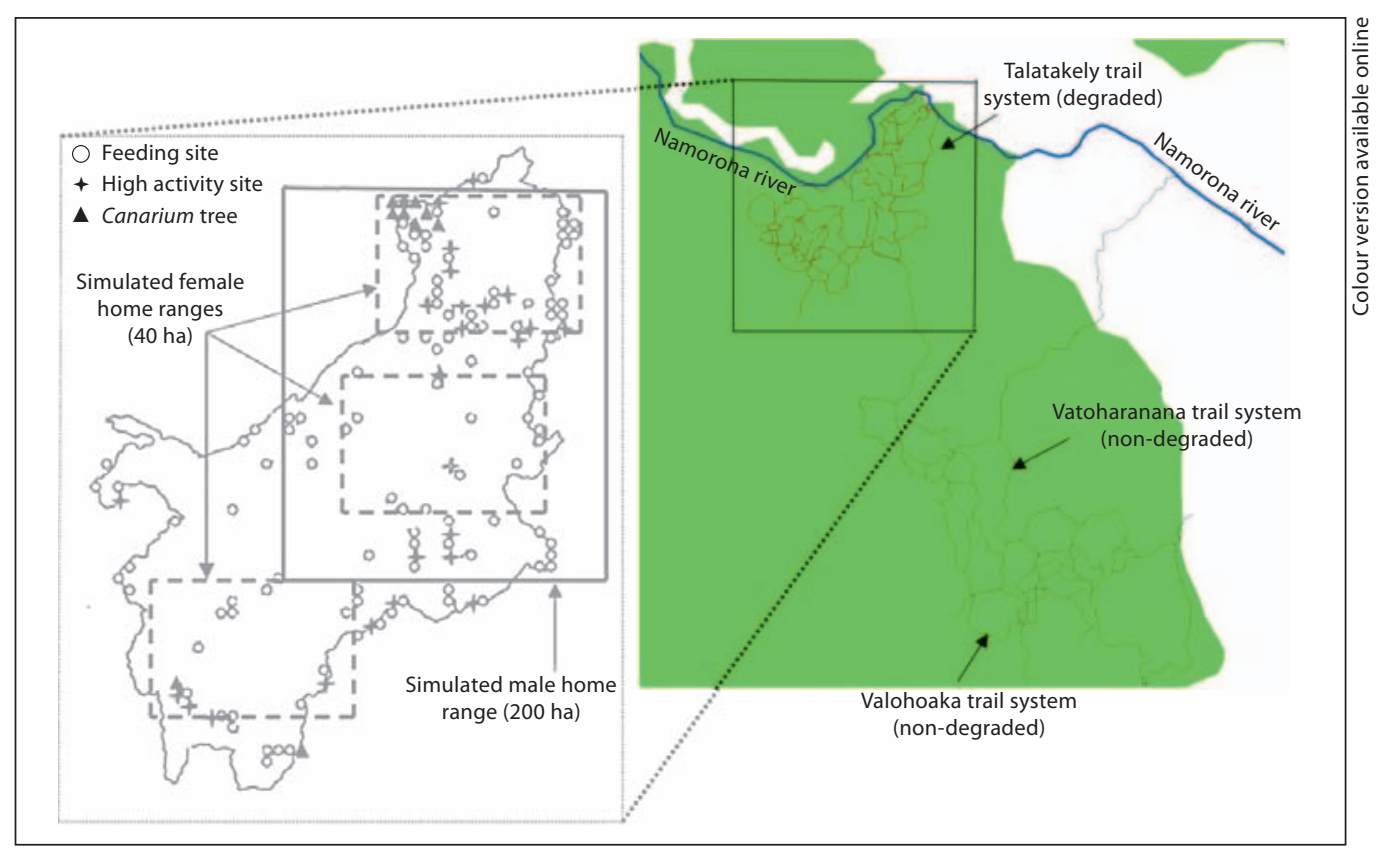

Fig. 1. Spatial location of 3 trail systems at RNP with inset of Talatakely, including randomly placed simulated home ranges (based on results from Sterling [1993]) for 1 male (solid line) and 3 female (dashed line) aye-ayes. The trail systems show the spatial relationship of degraded and non-degraded forest, as well as the protected area boundary for RNP.

RNP measuring habitat structure, forest production, biological diversity and forest composition, and found higher levels of forest quality, diversity and productivity for the Vatoharanana (non-degraded) study site compared to the Talatakely (degraded) study site at RNP. This disparity in forest composition, quality, diversity and productivity may be influencing aye-aye resource availability and population density. The Talatakely trail system features degraded forest [Balko and Underwood, 2005; Tecot, 2008] that, between 1986 and 1989, was selectively logged in some areas and intensively logged in others [Wright, 1997]. The Vohipaharara site is made up of high elevation humid forest with a relatively low canopy. We observed evidence of disturbance that had reportedly been occurring for years [Porter, 1998]. This disturbance, which included the extraction of natural resources by local villagers, forest fragmentation, poaching and human encroachment, likely has had adverse effects on numerous lemur species.

\section{Data Collection}

Farris [2006] conducted a preliminary study to compare feeding site density on trail to those areas off trail (straight line uncut transect through forest) in both degraded and nondegraded forests. Results showed little distinction in the average number of feeding sites per kilometre on trail (mean $=7.66 \pm 1.53)$ versus off trail (mean $=7.75 \pm 10.36)$ [Farris, 2006]; therefore, we conducted all surveys for the remainder of the study along trails to maximise the area covered. We surveyed half of all trails within each trail system. Before surveys began, we used trail maps and topographic maps of RNP to select trails for surveying. Trails were selected at the onset to ensure that all habitat types and landscape features (e.g. ridges, valleys) would be surveyed for all trail systems. For non-degraded forest, the trails on the outermost boundary of the trail system were often overgrown, and as a result these trails were not surveyed for this 

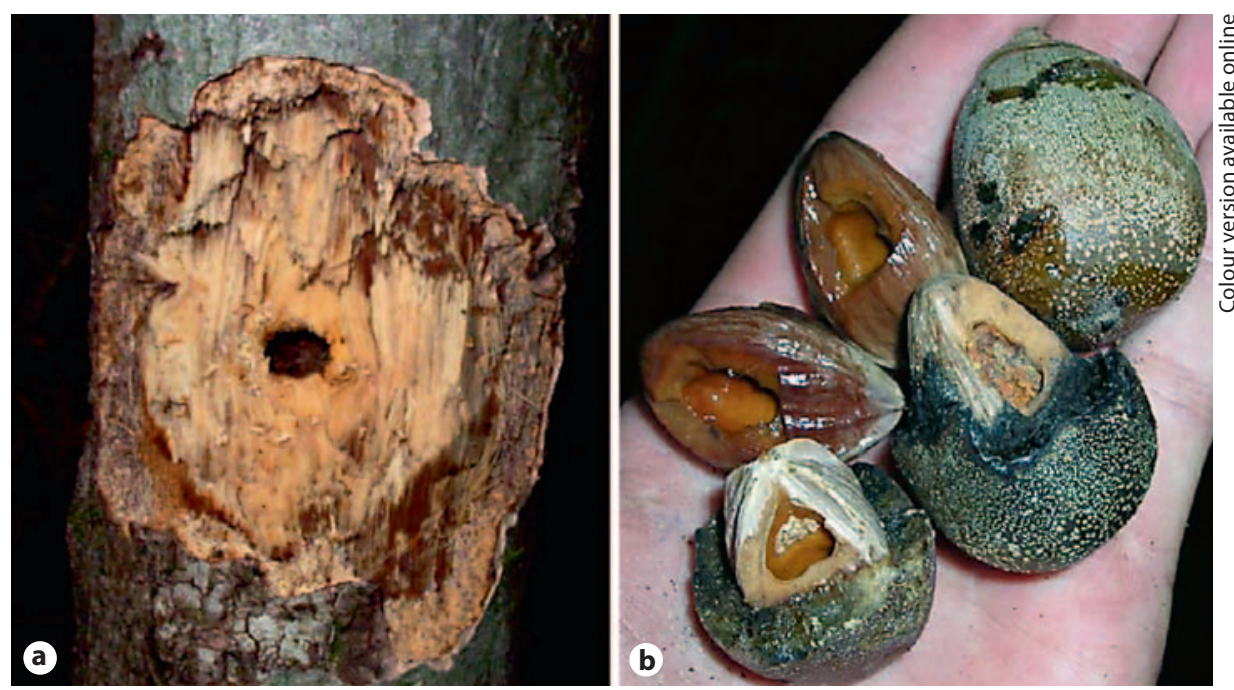

Fig. 2. Aye-aye secondary signs revealing distinctive incisor marks on dead wood (a) and $\mathrm{Ca}$ narium seeds (b). Photos taken by Z.J. Farris.

study. We ensured the same habitat types and landscape features were surveyed for each trail system. However, patches of bamboo habitat were sampled in degraded forest without any of similar size being found in non-degraded forest for surveys. Survey effort in bamboo habitat was minimal (approx. $250 \mathrm{~m}$ ) for degraded forest; therefore, any effect on our final analysis should be minimal. Each trail was surveyed just once, and survey effort was consistent across all trails to minimise influence and bias.

We worked with 2 Malagasy lemur expert guides to conduct a visual survey of aye-aye secondary signs at an average speed of $1.5 \mathrm{~km} / \mathrm{h}$ along 20 -metre strip transects. Ten metres were surveyed on each side of the trail, and in areas of dense vegetation researchers walked off trail to ensure the 20-metre survey distance remained consistent. We surveyed from ground level to the highest visible point of the canopy (typically $10-15 \mathrm{~m}$ ) in search of all 3 secondary signs: feeding sites, Canarium seeds and high activity sites. For this study, distinctive incisor markings on seeds of Canarium spp. or wood were classified as a feeding site. More specifically, to classify feeding sites on wood we used incisor marks near or around missing cambium layers, often with a 'channel' present (fig. 2a) [Sterling, 1993]. Additionally, tooth marks on Canarium seeds (fig. 2b) were carefully examined to ensure they were evidence of aye-aye feeding and not rodents [Goodman and Sterling, 1996]. We recorded any tree or downed log containing 10 or more incisor marks (around missing cambium layers with 'channel' present) as a 'high activity site'. In addition, we recorded the elevation range (50-metre intervals) of each feeding site using a handheld GPS unit. We recorded location and species of Canarium trees and noted presence of fruits. We recorded only trees with a diameter at breast height of $\geq 10 \mathrm{~cm}$.

\section{Data Analysis}

The number and length of trails differed in the 3 trail systems, leading to different amounts of survey effort for each trail system. To standardise results from each trail system, allowing for comparison across sites, we divided the total number of each measured variable by the number of metres surveyed, thus providing an average number of feeding sites, high activity sites and Canarium trees per kilometre for each trail surveyed. The average numbers of secondary signs per kilometre for each trail were then resampled, with replacement, using bootstrapping tech- 


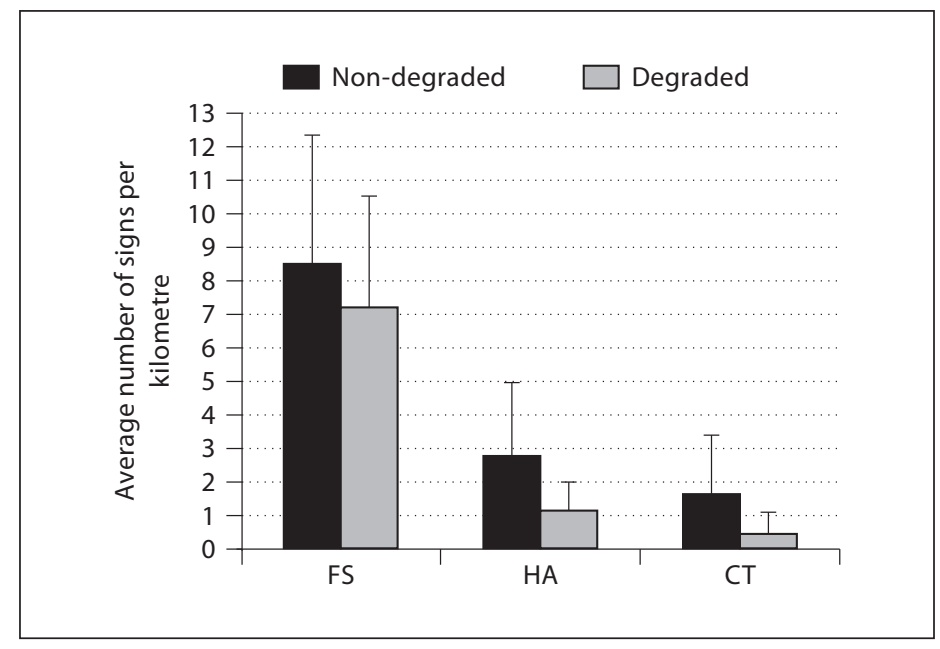

Fig. 3. Comparison of aye-aye presence and resource availability in degraded and non-degraded forest based on average feeding sites per kilometre (FS), average high activity sites per kilometre (HA) and average number of Canarium trees per kilometre (CT), with standard error shown for each variable.

niques ( $n=200 /$ trail system) to calculate average secondary signs, including standard error, for each trail system, thus allowing for comparison of degraded versus non-degraded forest. For the Vohipaharara transect, we calculated the average number of each measured variable for the single transect surveyed.

To compare feeding sites across degraded and non-degraded forests, we combined the average number of feeding sites per kilometre for Vatoharanana and Valohoaka (non-degraded) and the average feeding sites per kilometre for Talatakely and Vohipaharara (degraded) to compare using a normal approximation of the Mann-Whitney $U$ test ( $p \leq 0.05)$ [SAS Institute, 2001]. To compare high activity sites and Canarium trees across degraded and non-degraded forests, we used Welch's t test as a result of unequal variances for these 2 data sets.

To look for a correlation among the 3 measured variables across degraded and non-degraded forest, we compared average numbers of feeding sites, high activity sites and Canarium trees in degraded and non-degraded forest using Spearman's rank correlation test $(\mathrm{p}<0.05)$. Finally, we also used correlation analysis to evaluate the relationship between feeding site density and elevation.

\section{Results}

We surveyed $15.29 \mathrm{~km}$ in non-degraded forest (Vatoharanana and Valohoaka) and $23.94 \mathrm{~km}$ within degraded forest (Talatakely and Vohipaharara). The highest number of feeding sites came from the largest trail system, Talatakely $(\mathrm{n}=143)$, while the lowest came from the smallest area surveyed, Vohipaharara $(n=27)$. Non-degraded forest had a higher average of feeding sites compared to degraded forest (fig. 3); however, this difference was not significant (Mann-Whitney $U$ test: $n=2$, $\mathrm{Z}=-0.65, \mathrm{p}=0.52$ ). 
Table 1. Spearman rank-order correlation coefficients and associated probabilities for feeding sites (FS), high activity sites (HA) and Canarium trees (CT)

\begin{tabular}{lll}
\hline Variable & Non-degraded forest & Degraded forest \\
\hline FS $\cdot$ HA & $0.391(0.01)^{*}$ & $0.558(<0.01)^{*}$ \\
FS $\cdot$ CT & $0.017(0.91)$ & $0.282(0.08)$ \\
HA $\cdot$ CT & $0.140(0.38)$ & $0.223(0.17)$ \\
\hline
\end{tabular}

The relationship between feeding sites and high activity sites was significant across both degraded and non-degraded forests. ${ }^{*} \mathrm{p}<0.05$ : significant at the $95 \%$ confidence level.

Valohoaka, non-degraded forest, had almost 3 times more high activity sites per kilometre than all other sites surveyed $(3.81 \pm 2.09 \mathrm{SE} ; \mathrm{n}=27)$. As with feeding sites, the lowest number of high activity sites $(\mathrm{n}=2)$ came from the Vohipaharara transect. A comparison of degraded and non-degraded forests suggests a higher abundance of high activity sites for non-degraded forest (fig. 3; Welch's test: $\mathrm{n}=2, \mathrm{~F}=2.66, \mathrm{p}=$ $0.10)$.

Canarium madagascariense was the only tree species observed during this study. Vatoharanana $(3.79 \pm 2.23 \mathrm{SE})$, non-degraded forest, had more than twice the number of Canarium trees per kilometre compared to other sites. Further, as was the case for feeding sites and high activity sites, the two trail systems in non-degraded forest had more Canarium trees per kilometre than did the two in degraded forest. There was a trend toward more Canarium trees per kilometre in the non-degraded forest than the degraded forest (fig. 3; Welch's test: $\mathrm{n}=2, \mathrm{~F}=2.99, \mathrm{p}=0.08$ ). For each trail system, we mapped all feeding sites, high activity sites and Canarium trees to show patterns of aye-aye resource availability (fig. $4 \mathrm{a}-\mathrm{c}$ ).

A significant correlation was observed between feeding sites and high activity sites for both degraded and non-degraded forests (table 1). Overall, degraded forest had stronger correlations amongst all variables compared to non-degraded forest. The survey was conducted in terrain ranging from 950 to $1,200 \mathrm{~m}$. Feeding sites were found at all elevation ranges with the highest numbers coming from 1,000-1,050 m $(\mathrm{n}=30)$ and $1,150-1,199 \mathrm{~m}(\mathrm{n}=27)$ and the lowest numbers coming from 950$999 \mathrm{~m}(\mathrm{n}=6)$ and $1,200-1,249 \mathrm{~m}(\mathrm{n}=8)$; however, because of the dense vegetation, only 100 locations registered an accurate elevation reading. There was no effect of elevation on feeding site density $\left(n=5, R^{2}=0.06, p=0.908\right)$.

\section{Discussion}

\section{Feeding Sites}

We found evidence of higher aye-aye abundance and activity levels in non-degraded forest based on all 3 measured variables; however, in the case of feeding sites, it is important to note that aye-ayes have an extraordinary adaptability in foraging within numerous habitat types [Simons, 1993; Sterling, 1993, 2003; Ancrenaz et al., 1994; Andriamasimanana, 1994; Haring et al., 1994]. As a result, it is possible that 

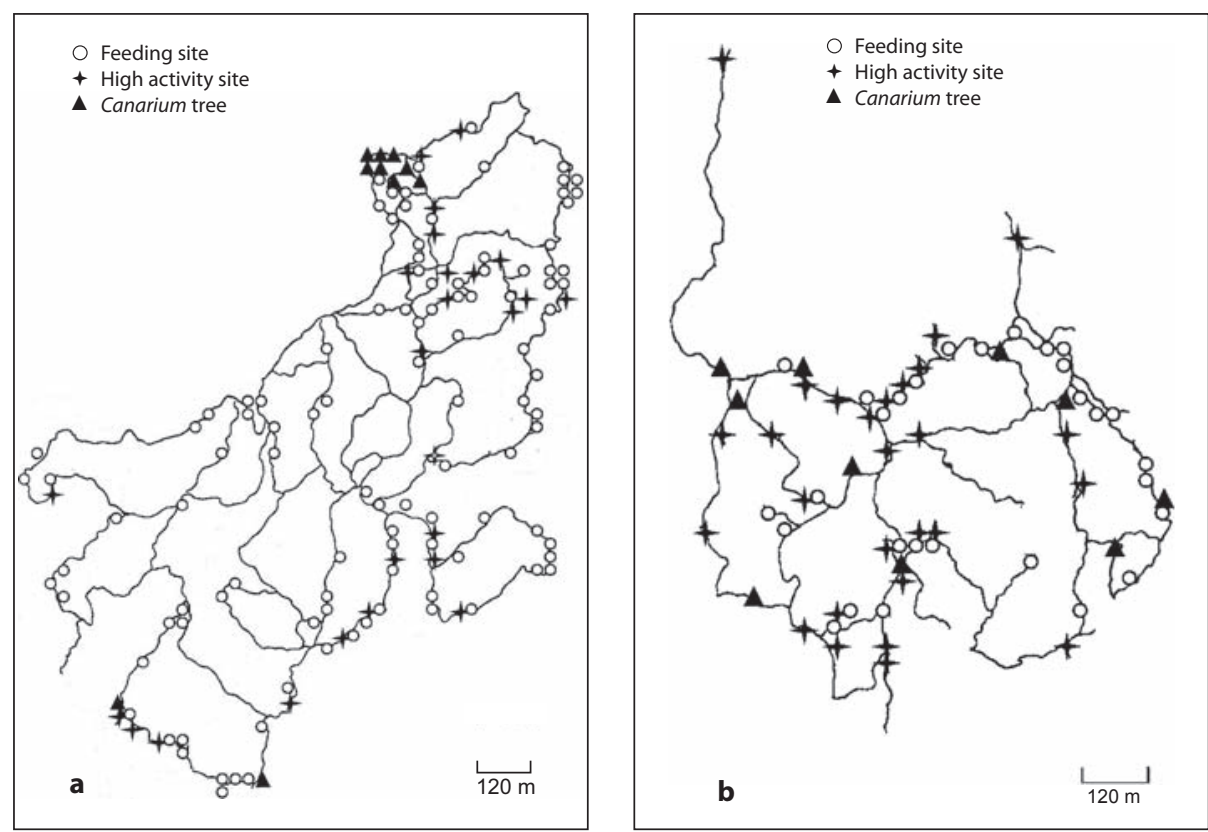

Fig. 4. Trail maps of RNP showing individual trails surveyed and secondary signs recorded for the Talatakely trail system (degraded forest, a), Valohoaka trail system (non-degraded forest, b) and Vatoharanana trail system (non-degraded forest, c). Symbols show the location of feeding sites, high activity sites and Canarium trees. Maps modified from original by G. Williams and C. Tan.

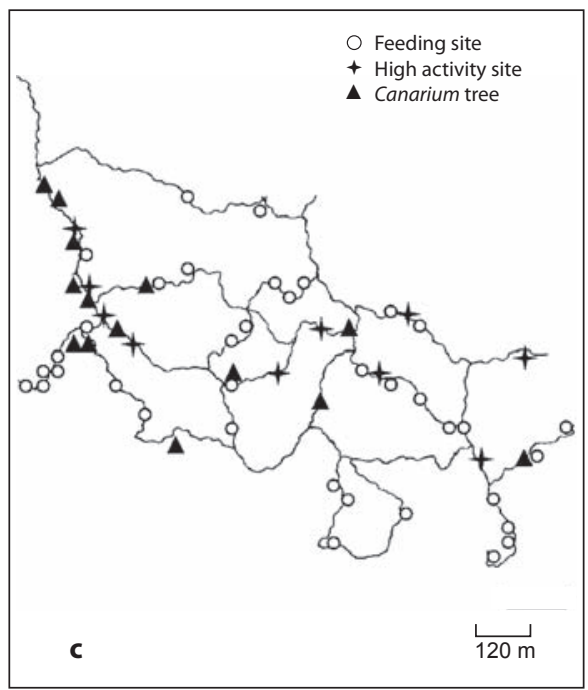

aye-ayes living within RNP have established home ranges without preference for a specific type of habitat or forest. After a study involving direct observation of ayeayes in Mananara-Nord, Andriamasimanana [1994, p. 45] concluded that 'aye-ayes seem to be very adaptable in terms of habitat preferences, in that they can exploit resources in primary, fragmented, or secondary forests'. While our results show that aye-ayes are apparently feeding less on imbedded larvae and/or Canarium seeds 
across degraded forest (fig. 3), it may be that aye-ayes are exploiting alternative resources to compensate for the limited availability of these resources or because another resource (e.g. Ravenala) is more plentiful and/or easier to access. Additionally, figure 3 reveals a widespread distribution of feeding sites throughout both degraded and non-degraded forests indicating wide-ranging activity throughout RNP.

\section{High Activity Sites}

We propose an optimal foraging hypothesis [MacArthur and Pianka, 1966] to explain the higher aye-aye activity at highly productive feeding sites. The more than twofold increase in highly productive and established feeding sites between nondegraded $(2.78 \pm 2.15$ sites $/ \mathrm{km})$ and degraded forest $(1.15 \pm 0.83$ sites $/ \mathrm{km})$ suggests higher aye-aye activity because of greater resource availability within non-degraded forest at RNP, which could be related to higher population densities. However, further considerations must be made concerning other explanations (e.g. overlapping home ranges, use of other food sources).

We assume here that higher activity at a single site is correlated with an increase in potential food resources. However, not every gnaw mark is evidence of a successful feeding by a single aye-aye given that aye-ayes will often open cavities with no prey or open a single cavity at multiple locations [Erickson, 1994] and individuals may overlap home ranges [Sterling, 1993]. Without knowing the number of aye-ayes within the area, the actual number of prey per cavity, or whether or not each gnaw mark was a successful feeding event, we argue this high number of marks $(\geq 10)$ at a single site shows not only higher activity, but also could be considered evidence of an individual aye-aye feeding optimally at a single site [MacArthur and Pianka, 1966]. Additionally, we present the location of 'aye-aye trees' (sites containing a substantial number of gnaw marks) as possible evidence of individual aye-ayes feeding optimally, in this case through multiple revisits over seasons. Sterling [1993] observed ayeayes returning to the same productive sites over the course of a season; however, she also observed multiple individuals visiting the same highly productive sites over seasons. Direct observations of aye-aye feeding behaviour and ranging patterns in rainforest habitat are needed to definitively conclude that these high activity sites provide an example of optimal foraging by aye-ayes. We suggest these aye-aye trees can play a major role in locating and viewing aye-ayes for future studies.

We propose that the distribution of high activity sites is an important factor for measuring aye-aye activity. High activity sites are both more prevalent and more widely dispersed in non-degraded compared to degraded forest (fig. $4 a-c)$. These results provide evidence of higher aye-aye activity and a wider-ranging presence of aye-ayes for non-degraded forest compared to degraded forest. It is possible that nondegraded forest has an increase in resource availability, resulting in differences in aye-aye home range size across these two forest types. However, further research is needed to understand resource use and availability, as well as home range size and overlap across degraded and non-degraded forests.

\section{Canarium}

Given the importance of Canarium seeds in the diet of aye-ayes throughout Madagascar [Iwano and Iwakawa, 1988; Iwano et al., 1991; Sterling, 1994; Goodman and Sterling, 1996], the low number and limited dispersion of Canarium within de- 
graded forest $(0.46 \pm 0.62$ Canarium trees $/ \mathrm{km} ; \mathrm{n}=13)$, compared to non-degraded forest $(1.61 \pm 1.78$ Canarium trees $/ \mathrm{km} ; \mathrm{n}=24)$, may be a problem as it limits the availability of this key resource for aye-ayes. Moreover, the endangered frugivorous black-and-white ruffed lemur (Varecia variegata) counts Canarium as one of its major food sources [Balko, 1998; Vasey, 2003] and, in turn, acts as an important seed disperser for this tree species. In fact, lack of Canarium in degraded forest may be a strong factor limiting population densities of both aye-ayes and black-and-white ruffed lemurs within degraded forests at RNP. However, a more thorough understanding of resource use and availability for aye-ayes occupying degraded forest is needed to explore this hypothesis further.

We predict that aye-ayes living in degraded forest at RNP show greater plasticity in their foraging to compensate for the lower density of nutrient-rich Canarium seeds. Ancrenaz et al. [1994] observed aye-ayes using nectar from Ravenala madagascariensis (traveller's tree; Strelitziaceae) as their primary food source in the degraded habitat around Mananara-Nord, in north-eastern Madagascar. Data need to be collected on the use of Ravenala trees (and other available food sources) to provide a more thorough understanding of aye-aye resource utilization across degraded and non-degraded rainforest.

To demonstrate the low abundance of Canarium (and high activity sites) for ayeayes occupying degraded habitat at RNP, we constructed possible home ranges across the Talatakely trail system based on data from Sterling [1993] (male average home range $=200$ ha; female average home range $=40$ ha; fig. 1 ). These home ranges show how low abundance and limited dispersion of resources in degraded forest may result in alteration of aye-aye foraging strategies, shifts in home range size and/or decreases in population density. Consequently, other factors, such as population size, access to mates and food source utilization, should be examined within RNP to investigate activity patterns and home range dynamics for individuals across habitat types.

We included incisor marks on Canarium seeds with incisor marks on wood to indicate aye-aye 'feeding sites'. Using incisor marks on seeds alone as a single, independent secondary sign or to measure presence/absence of Canarium across study sites would create a bias as these trees at RNP fruit asynchronously [Goodman and Sterling, 1996]. As a result, we recorded the number of trees across a forest site so as to provide a key indicator of aye-aye distribution as it relates to resource availability. Presence of Canarium trees does not directly indicate presence of aye-ayes; however, given that (1) recent aye-aye feeding activity was recorded in the proximity of all $\mathrm{Ca}$ narium trees recorded for this study (fig. $4 \mathrm{a}-\mathrm{c}$ ), (2) incisor marks were found on seeds from previous fruiting seasons for almost all trees recorded in this study and (3) ayeayes are known to consume Canarium seeds heavily when in fruit [Sterling, 1994], we suggest the use of Canarium trees, as a measure of resource availability, should be used as an additional indicator when surveying for aye-aye distribution across a forest site.

\section{Elevation}

The results of this study do not show a strong relationship among feeding sites and elevation. These results provide further evidence of the aye-aye's ability to occupy numerous habitat types throughout Madagascar. Future research could investigate further this issue by looking at preferred resource availability (such as $\mathrm{Ca}$ narium) at higher elevations, as this might be a limiting factor in aye-aye population densities. 


\section{Conclusion}

In this study we presented new methods for investigating aye-aye presence and distribution. Further, we tested the prediction that aye-aye activity, based on secondary signs and resource availability, is greater in non-degraded forest. With these data it is now possible to determine which areas are used by aye-ayes within the forest, the degree to which each area is used, and the level of resource availability based on the presence of Canarium trees (fig. $4 \mathrm{a}-\mathrm{c}$ ). In addition, we have collected preliminary data to help us understand why aye-ayes might be choosing a particular habitat over others.

Most surveys attempting to estimate density of this lemur within an area simply make note of occurrence or absence of aye-ayes based on single feeding sites/gnaw marks or brief glimpses of individuals. The results of this study show the presence of aye-ayes across both degraded and non-degraded forests with an increase in feeding sites, as well as trends towards significant increases in high activity sites and Canarium trees, across non-degraded forest (fig. 3). These findings could potentially be correlated with higher population density within non-degraded forest; however, more in-depth analyses are needed to make that determination. The results of this study show that future surveys looking for aye-aye presence (or estimating density) could benefit from considering other factors such as number of Canarium trees and total number of incisor marks at each individual site.

Perhaps the most significant result of this study comes from data collected on Canarium, which show low abundance and limited dispersion in degraded forest (fig. 4a). Moreover, the few trees recorded for degraded forest show a clumped pattern. The methods we used for analysis required the averaging of Canarium trees over the entire trail system. As a result, the plight of this tree species may be even more negatively skewed for degraded forest than these results show. These results highlight the mounting need for conserving and increasing Canarium trees within RNP and throughout rainforest habitat in Madagascar. This issue is accentuated when considering the broad use of this tree species by aye-ayes, the endangered black-and-white ruffed lemur and numerous other lemur species. The results and conclusions of this study, although preliminary, are based on a large number of secondary signs and will aid in future attempts to estimate aye-aye population densities and habitat utilization within RNP.

\section{Acknowledgements}

We would like to thank our guides Jean Baptiste Velotsara and Justin Rakotongatovo. We are appreciative of the staff of the Centre ValBio, the Association Nationale pour la Gestion des Aires Protégées, the Institute for the Conservation of Tropical Environments (Stony Brook) and the Madagascar Institut pour la Conservation des Ecosystèmes Tropicaux for their assistance in this project. Financial and travel support was provided by the Arkansas Game and Fish Commission Conservation Scholarship and Tiger Aspect Productions. 


\section{References}

Ancrenaz M, Lackman-Ancrenaz I, Mundy N (1994). Field observations of aye-ayes (Daubentonia madagascariensis) in Madagascar. Folia Primatologica 62: 22-36.

Andrainarivo C, Andriaholinirina VN, Feistner A, Felix T, Ganzhorn J, Garbutt N, Golden C, Konstant B, Louis E Jr, Meyers D, Mittermeier RA, Perieras A, Princee F, Rabarivola JC, Rakotosamimanana B, Rasamimanana H, Ratsimbazafy J, Raveloarinoro G, Razafimanantsoa A, Rumpler Y, Schwitzer C, Thalmann U, Wilmé L, Wright P (2009). Daubentonia madagascariensis. In IUCN: IUCN Red List of Threatened Species. Version 2009.1. www.iucnredlist.org (accessed September 23, 2009).

-Andriamasimanana M (1994). Ecoethological study of free-ranging aye-ayes (Daubentonia madagascariensis) in Madagascar. Folia Primatologica 62: 37-45.

Balko EA (1998). A Behaviorally Plastic Response to Forest Composition and Logging Disturbance by Varecia variegata variegata in Ranomafana National Park, Madagascar. Dissertation, State University of New York, Syracuse.

Balko EA, Underwood HB (2005). Effects of forest structure and composition on food availability for Varecia variegata at Ranomafana National Park, Madagascar. American Journal of Primatology 66: $45-70$.

Erickson CJ (1994). Tap-scanning and extractive foraging in aye-ayes (Daubentonia madagascariensis). Folia Primatologica 62: 125-135.

Farris ZJ (2006). Presence and Distribution of Aye-Ayes (Daubentonia madagascariensis) within Ranomafana National Park, Madagascar. Thesis, University of Arkansas at Little Rock.

Feistner AC, Schmid J (1999). Lemurs of the Réserve Naturelle Intégrale d'Andohahela, Madagascar. Fieldiana: Zoology 94: 269-283.

Ganzhorn JU, Rabesoa J (1986). Sightings of aye-ayes in the eastern rainforest of Madagascar. Primate Conservation 7: 45.

Gibson KR (1986). Cognition, brain size, and the extraction of embedded food resources. In Primate Ontogeny, Cognitive and Social Behavior (Else JG, Lee LC, eds.), pp 93-105. Cambridge, Cambridge University Press.

Glaw F, Vences M, Randrianiania RD (2008). Killed aye-aye (Daubentonia madagascariensis) exposed on the gallows in northeastern Madagascar. Lemur News 13: 6-7.

Goodman SM, Sterling EJ (1996). The utilization of Canarium (Burseraceae) seeds by vertebrates in the Réserve Naturelle Intégrale d'Andrigitra, Madagascar. Fieldiana: Zoology 85: 83-89.

Grassi C (2001). The Behavioral Ecology of Hapalemur griseus griseus: The Influences of Microhabitat and Population Density on this Small-Bodied Prosimian Folivore. Doctoral dissertation, University of Texas at Austin.

Haring DM, Hess WR, Coffman BS, Simons EL, Owens TM (1994). Natural history and captive management of the aye-aye at the Duke University Primate Center, Durham. The Zoological Society of London International Zoo Yearbook 33: 219-228.

Iwano T, Iwakawa C (1988). Feeding behaviour of the aye-aye (Daubentonia madagascariensis) on nuts of ramy (Canarium madagascariensis). Folia Primatologica 50: 136-142.

Iwano T, Randalana R, Rakotoarisoa G (1991). Ecology of the aye-aye (Daubentonia madagascariensis). I. Distribution. In Primatology Today (Ehara A, Kimura T, eds.), pp 41-42. Amsterdam, Elsevier.

MacArthur RH, Pianka ER (1966). On optimal use of a patchy environment. The American Naturalist 100: 603-609.

Milliken GW, Ward JP, Erickson CJ (1991). Independent digit control in foraging by the aye-aye (Daubentonia madagascariensis). Folia Primatologica 56: 219-224.

Petter JJ (1977). The aye-aye. In Primate Conservation (Rainier P III, Bourne GH, eds.), pp 37-57. New York, Academic Press.

Pollock JI, Constable ID, Mittermeier RA, Ratsirarson J, Simons H (1985). A note on the diet and feeding behavior of the aye-aye Daubentonia madagascariensis. International Journal Primatology 6: $435-447$.

Porter LM (1998). Influences on the distribution of Lepilemur microdon in the Ranomafana National Park, Madagascar. Folia Primatologica 69: 172-176.

SAS Institute Inc. (2001). Version 9.1. Cary, SAS

Simons E (1993). Discovery of western aye-aye: lemurs in the wild. Lemur News 1: 6.

Sterling EJ (1993). Behavioral Ecology of the Aye-Aye (Daubentonia madagascariensis) on Nosy Mangabe, Madagascar. Dissertation, Yale University, New Haven.

Sterling EJ (1994). Aye-ayes: specialists on structurally defended resources. Folia Primatologica 62: 142 154.

Sterling EJ (2003). Daubentonia madagascariensis, aye-aye. In The Natural History of Madagascar (Goodman SM, Benstead JP, eds.), pp 1348-1351. Chicago, University of Chicago Press. 
Sterling EJ, Feistner AC (2000). Aye-aye (Daubentonia madagascariensis). In Endangered Animals: A Reference Guide to Conflicting Issues (Reading R, Miller B, eds.), pp 45-48. Westport, Greenwood.

Sterling EJ, Povinelli DJ (1996). Tool use, aye-ayes, and sensorimotor intelligence. Folia Primatologica 70: $8-16$

Sterling EJ, Dierenfeld ES, Ashbourne CJ, Feistner AT (1994). Dietary intake, food composition and nutrient intake in wild and captive populations of Daubentonia madagascariensis. Folia Primatologica 62: 115-124.

Tecot S (2008). Seasonality and Predictability: The Hormonal and Behavioral Responses of the Red-Bellied Lemur, Eulemur rubriventer, in Southeastern Madagascar. Dissertation, University of Texas at Austin.

Vasey N (2003). Varecia, ruffed lemurs. In The Natural History of Madagascar (Goodman SM, Benstead JP, eds.), pp 1332-1336. Chicago, University of Chicago Press.

White FJ, Overdorff DJ, Balko EA, Wright PC (1995). Distribution of ruffed lemurs (Varecia variegata) in Ranomafana National Park, Madagascar. Folia Primatologica 64: 124-131.

Wright PC (1995). Demography and life history of free-ranging Propithecus diadema edwardsi in Ranomafana National Park, Madagascar. International Journal of Primatology 16: 835-854.

Wright PC (1997). The future of biodiversity in Madagascar: a view from Ranomafana National Park. In National Change and Human Impact in Madagascar (Goodman SG, Patternson BD, eds.), pp 381-405. Washington, Smithsonian Institution Press. 